\title{
Idilični prostori kot drugi prostori v pripovedni prozi Pavline Pajk
}

\author{
JOŽICA ČEH STEGER \\ Univerza v Mariboru, Filozofska fakulteta, Koroška cesta 160, \\ SI-2000Maribor, jozica.ceh@um.si
}

\begin{abstract}
V izbrani pripovedni prozi Pavline Pajk so predstavljeni idilični prostori (vrtovi, gaji, ribniki in gozdne jase), ki s posameznimi prvinami spominjajo na locus amoenus. Praviloma se pojavljajo v vlogi romantičnih heterotopij kot iluzijski prostori počitka, branja, ročnega dela, premišljevanja, zaupnih pogovorov, uživanja na svežem zraku ali ljubezenskih srečanj, vsaj na enem mestu pa je opazna tudi njihova razgradnja. Idilični prostori, v katere so umeščeni ženski liki, opozarjajo obenem na tradicionalni koncept istovetenja ženske z naravo, kar se pokaže v prevladujoči rastlinski oziroma cvetni metaforiki za žensko, temelječi na konceptualni metafori ŽENSKA JE RASTLINA. Vendar ta metafora ne govori le o ženski ali o konvencionalnosti pisateljičinega sloga, temveč sporoča tudi prevladujoče predstave o razumevanju ženske $\mathrm{v}$ družbeno-kulturnem kontekstu 19. stoletja.
\end{abstract}

The narrative prose by Pavlina Pajk speaks of idyllic spaces (gardens, ponds and forest clearings, etc.), which are in some of their elements reminiscent of the locus amoenus. As a rule they appear in the role of romantic heterotopias, i. e. as spaces of rest, reading, knitting and sewing, places of reflection, confidential conversations, and places for enjoying the fresh air or amorous encounters. In the novel Slučaji usode (Strikes of Fate) the idyllic image of the garden is also decomposed. Idyllic spaces in which female characters are placed thus remind us of the traditional concept of the integration of woman with nature, which is featured in the predominant plant metaphors for women based on the conceptual metaphor WOMAN IS A PLANT. However, this metaphor does not speak only of a woman, or of the conventionality of the author's style, but announces also the prevailing understanding of the perceptions of women in the socio-cultural context of the 19th century.

Ključne besede: Pavlina Pajk, pripovedna proza, idilični prostori, heterotopije, locus amoenus, vrtovi, rastlinska metafora

Key words: Pavlina Pajk, narrative prose, idyllic spaces, heterotopias, locus amoenus, gardens, plant metaphor 


\section{Uvod $^{1}$}

Povečano zanimanje za povezave med književnostjo in zemljepisnimi prostori je v novejšem času opazno v razmahu empiričnih in sistemskih metod literarne vede kakor tudi geopoetike, ${ }^{2}$ ki se posveča poetiki prostora $\mathrm{v}$ razponu od natančnega referiranja na empirične zemljepisne prostore do povsem fingirane, kulturno konstruirane zemljepisne predmetnosti. Na drugačno razumevanje prostora v literarni vedi je odločilno vplival Michel Foucault. Že v šestdesetih letih prejšnjega stoletja je uvedel pojem heterotopije ${ }^{3}$ in $\mathrm{z}$ njim poimenoval tako imenovane druge prostore, za katere je značilno, da »so v odnosu z vsemi drugimi položaji, vendar na tak način, da suspendirajo, nevtralizirajo ali sprevračajo celoto odnosov, ki so prek njih načrtovani, zrcaljeni ali reflektirani« (Foucault 2007: 217). Drugi prostori so po Foucaultu dveh vrst; utopije kot položaji brez realnih krajev in heterotopije kot dejanski kraji, ki so drugačni od vseh krajev in so načrtovani v sami instituciji družbe. Heterotopije so razložene kot »dejansko realizirane utopije, v katerih so realni položaji, vsi drugi realni položaji, ki jih je mogoče najti znotraj kulture, hkrati reprezentirani, spodbijani in sprevrnjeni« (Foucault 2007: 217). Zanje je značilno, da obstajajo v vseh družbah in civilizacijah, vezane so na razreze časa, njihovo delovanje je družbeno in zgodovinsko ${ }^{4}$ pogojeno, imajo moč, da lahko na enem kraju vzpostavijo več nezdružljivih prostorov, obenem predpostavljajo tudi sistem odpiranja in zapiranja, kar pomeni, da so izolirane in hkrati prepustne (Foucault 2007: 218-221).

K novejšim vidikom preučevanja prostora se uvršča tudi naratologija študijev spola, ki je med drugim opozorila, da se v različnih oblikah zaznavanja, opisovanja in vrednotenja literarnih prostorov ne izražajo le emocije, ideologije ali podzavestne želje, marveč tudi spolne orientacije in konotacije (Würzbach 2004: 49). Kulturno pogojena moč spolne matrice je posebej ugotovljena v sim-

${ }^{1}$ Razprava je nastala v okviru raziskovalne skupine Slovensko jezikoslovje, književnost in poučevanje slovenščine (P6-0156).

${ }^{2}$ Z geopoetiko označuje Susi K. Frank (2010: 30-31) literarno-umetniške postopke za pomensko in simbolno ubeseditev zemljepisnega prostora, tj. različne besedilne postopke, motive, topose, mitopoetske strategije, narativne vzorce, specifične kronotope, medijske (pisne, slikovne, diagramske idr.) predstavitve prostora idr. Zbornik Geopoetiken (Berlin 2010), ki sta ga uredili Magdalena Marszałek in Sylvia Sasse, opozarja, da so po padcu Berlinskega zidu in po politični preureditvi zemljevida Evrope geopoetske raziskave še posebej prisotne v raziskovanju vzhodno- in srednjeevropskih literatur. Novejše raziskave o prostoru slovenske literarne kulture prinaša tematska številka Slavistične revije iz leta 2012

${ }^{3}$ Michel Foucault je ta pojem prvič zapisal v predgovoru k Les mots et les choses in natančneje razložil v radijskem predavanju, ki ga je imel 14. marca 1967. Besedilo je bilo napisano v Tuniziji in ga je za objavo odobril šele leta 1984. Objavljeno je bilo pod naslovom Des espaces autres v reviji Architecture, Mouvement, Continuité. V slovenščino je prevedeno pod naslovom O drugih prostorih (Foucault 2007: 214).

${ }^{4}$ Za primitivne družbe značilne krizne heterotopije (prostori adolescence, rojstva, umiranja idr.) v sodobni družbi izginjajo, nastajajo pa heterotopije deviantnosti (zapori, domovi za ostarele, psihiatrične ustanove idr.) (Foucault 2007: 219). 
bolizaciji prostorov, ki krajevno niso jasno določeni, a se nanašajo na konkretne prostorske izkušnje, kot so domovina, tujina, narava in mesto (Würzbach 2004: 50). Tradicionalni koncept narave je povezan s stereotipnimi predstavami o ženski, kot so denimo nepreglednost, podrejenost, nagon ali cikličnost življenja in smrti (Würzbach 2004: 50). Po drugi strani so v mesto kot civilizacijski protipol narave vgrajene stereotipne predstave o moškem in je tradicionalno zasnovano kot prostor intelekta, kulture in civilizacije, ${ }^{5}$ lahko tudi kot prostor poželenja in osvajanja. V primerjavi s tem je bilo ženskam, ki so bile v zahodni kulturi vse do konca 19. stoletja omejene na zasebno sfero, mesto predstavljeno kot prostor nevarnosti in ogroženosti.

Würzbach nadalje navaja, da je s spolno delitvijo prostorov povezano tudi različno obnašanje v njih. Hiša na primer je bila ženskam vse do začetka 20. stoletja edini družbeno dodeljen prostor in so jo le redko zapuščale, medtem ko so moški iz nje odhajali $\mathrm{v}$ javne prostore in se vanjo vračali kot $\mathrm{v}$ prostor miru in počitka. Čeprav je hiša tradicionalno družbeno-kulturno pojmovana kot prostor družinske varnosti, lahko postane tudi prostor psihičnega ali fizičnega nasilja, ki ga izvaja močnejši nad šibkejšim. Zato doživljajo ženske hišo precej ambivalentno, na eni strani kot prostor pričakovane ljubezni in na drugi strani kot prostor oropane svobode, fizičnih in psihičnih groženj, zahtev in pogojev (Würzbach 2004: 53).

\section{Ljubezen in druge teme}

V izbranih pripovednih besedilih Pavline Pajk (Odlomki ženskega dnevnika, Zora 1876; Roka in srce, Kres 1881; Arabela, Kres 1885; Planinska idila, Knezova knjižnica 1895, Slučaji usode, 1897) so v ospredju ljubezenske zgodbe deklet iz meščansko-trškega okolja, v katerih se razkrivajo prvine sentimentalnega pripovedništva. ${ }^{6} \mathrm{~V}$ kratki pripovedi Občutki na novega leta dan (Zora 1876) se je pisateljica spraševala po smislu svojega in človeškega življenja. Odgovor je iskala pri pesnikih in mislecih (pri Byronu, Sokratu, Petrarki idr.), slednjič se je odločila za skrivno sporočilo narave: Ljubi, misli in delaj. To misel je nato sprejela za geslo svojega (tudi občečloveškega) življenja in pojasnila, da si pravega dela ni mogoče predstavljati brez ljubezenskega čutenja in mišljenja, a da je za ženske vendarle najpomembnejša ljubezen $v$ smislu najmilejšega in najblažjega čustva, ki omogoči umiritev srca in pravo srečo. ${ }^{7}$ Obenem je dodala,

\footnotetext{
${ }^{5} \mathrm{~V}$ Župančičevi Dumi na primer so spolno stereotipno označeni mesto, narava in vaška kultura.

${ }^{6} \mathrm{O}$ prvinah sentimentalnega pripovedništva v romanu Arabela Pavline Pajk prim. npr. razpravo Trivialno in/ali sentimentalno? Katje Mihurko Poniž (2011: 67).

${ }^{7}$ Ljubezen kot najvišjo vrednoto in največjo zemeljsko srečo, ki jo lahko doseže človek, je Pavlina Pajk razglašala tudi v svojih aforizmih. Verjela je $v$ čisto in nesebično ljubezen, takšno, ki vse žrtvuje in vse odpušča, obenem pa je bila prepričana, da je za žensko najpomembnejša vzgoja srca in da vodita k resnični ter trajni sreči krepost in vera (Erjavec/Flerè 1926: 120).
} 
da želi biti »do slednjega svojega vzdihljaja vredna hčerka matke Slovenije« (Pajk 1876: 123), kar moremo razumeti kot sporočilo, da je njeno literarno ustvarjanje prav tako zavezano slovenstvu, kakor je denimo poudarjeno v Levstikovem literarnem programu Popotovanje iz Litije do Čateža, ki pa je - kot vemo - odklanjal tematizacijo meščanstva, pisanje povesti po francoskih in nemških zgledih, odsvetoval obširno opisovanje krajev, če ni nujno potrebno, ter se posebej obregnil ob potujčene meščanke, katerih slovenščina bi v romanih ne zvenela pristno (Levstik 1994: 123). Miran Hladnik (1981: 263) ugotavlja, da so ženske literarne osebe v pripovedni prozi Pavline Pajk, ki je nastajala po vzorcu sentimentalnega pripovedništva, stereotipno oblikovane. Katja Mihurko Poniž pa opozarja, da je pisateljica sentimentalni vzorec tudi modificirala (Mihurko Poniž 2011: 70). Ženski literarni liki Pavline Pajk verjamejo v zakon iz ljubezni, bolj ali manj odločno pa zavračajo sklenitev zakonske zveze iz materialnih razlogov. Irma iz novele Odlomki ženskega dnevnika sprva zavrne morskega stotnika, s katerim bi jo iz gmotnih razlogov želela poročiti mačeha, in želi raje ostati sama. Ko se čez čas v njej prebudi ljubezensko hrepenenje, stotnik zanjo ni več dosegljiv, saj mora postati duhovnik. Melita iz novele Roka in srce se sicer poroči s precej starejšim in bogatim markizom, vendar staršem da vedeti, da so jo prodali. Moževo ljubezen sprejme šele, ko se o tem prepriča sama in spozna, da mu je naredila krivico. Arabela iz istoimenskega romana bi se morala poročiti z bratrancem Samuelom zato, da bi ostal njen denar v stričevi hiši, vendar Samuela kljub zaroki zavrne in posluša glas svojega srca. Tudi rejenka Alenka iz Planinske idile ne uresniči tetinih in stričevih načrtov, da bi se poročila z bratrancem Hilarijem, ker do njega ne čuti ljubezni.

Ob ljubezenskih temah se $\mathrm{v}$ izbranih besedilih razbirajo zanimivi diskurzi o ženski lepoti in položaju neporočenih žensk v družbi (Odlomki ženskega dnevnika), o vegetarijanstvu (Arabela), o predsodkih do Židov (Arabela), o nasprotju med mestom in podeželjem, o skrbi za zdravo življenje (Roka in srce, Arabela, Planinska idila), o razmahu planinskega turizma (Planinska idila) idr. Precej kritičen diskurz o položaju neporočenih žensk v družbi zasledimo v noveli Odlomki ženskega dnevnika. Potem ko Irma zavrne stotnika, ki ji je bil predviden, in ji mačeha očita, da se bo njena soba kmalu spremenila v tiho svetišče starodeviških vzdihljajev, začne razmišljati o neporočenih ženskah, izrazi globoko sočutje do njih in se sprašuje, zakaj so v družbi zaničevane in zasmehovane. Dekletom obenem svetuje, naj se ne poročajo iz bojazni pred samskim stanom, ker je za žensko manjša nesreča, če ostane neporočena, kot da vstopi v zakonsko zvezo brez ljubezni, kar je ponazorjeno z metaforiko cvetja in trnja:

Zato se ni čuditi, ako toliko deklet, samo da se izogne temu deviškemu posmehovanju, stopi v zakonski stan brez volje, brez ljubezni, trnje potem žanjoč tam, kjer so si nekdaj obetale nabirati samih cvetic ljubezni. Ali revice niso slutile, da je slednja nesreča večja od prve! Zato rajši »stara devica«, nego nesrečna ženica! (Pajk 1876: 160.) 
Pripovedi Pavline Pajk mestoma opozarjajo na neživljenjskost dekliške vzgoje in njihovo pomanjkljivo izobrazbo. Vzgojna in moralna pravila so meščanskim dekletom iz 19. stoletja narekovala, da so živela precej odmaknjeno od stvarnega življenja. Pred poroko se niso kaj prida pojavljala v javnosti, prav tako niso kaj dosti potovala. O Meliti iz novele Roka in srce beremo, da se ji je šele na poročnem potovanje ponudila prva priložnost, da se je seznanila $\mathrm{Z}$ lepoto in s posebnostmi drugih krajev, ki si jih je z zanimanjem in užitkom ogledovala. V isti noveli se pojavi vzgojiteljica Leonora in potoži o svojem pomanjkljivem poznavanju zemljepisa.

\section{Soba - zavetišče in svetišče devištva}

V pripovedništvu Pavline Pajk je večkrat opisano, kako se dekle zapre v sobo, piše dnevnik ali sloni ob oknu in žalostno zre v daljavo. Tak primer najdemo tudi v noveli Odlomki ženskega dnevnika. ${ }^{8}$ Pripovedovalka Irma, vzgojena kot rastlina $\mathrm{v}$ rastlinjaku, je začela pisati dnevnik o svojem čustvenem življenju, potem ko ji je mačeha na osemnajsti rojstni dan zaželela poštenega soproga in se je lahko preselila v svojo sobo, kar je navedla kot prvo večjo spremembo v svojem življenju. Na prvem plesu je z obleko in rdečo rožo v dolgih črnih laseh zbudila občudovanje, še posebej pri morskem stotniku. Po vrnitvi domov se je svoje koketnosti sramovala. Kot vzgojni korektiv se nato pojavi materino pismo, v katerem ji le-ta pred smrtjo naroča, naj varuje deviško lepoto, kar je ubesedeno s prispodobo osute rože: »Deviška duša je podobna razcvelej roži: utrgaj jej eno peresce, vsa druga se koj za njo ospo« (Pajk 1876a: 137). Irma se je nato zapirala $v$ svojo sobo. Ta je postala njeno zavetišče pred zunanjim svetom in prostor, v katerem je želela vzgojiti srce oziroma obvladati čustvo.

V noveli Roka in srce, ki je bila objavljena v Kresu leta 1881, postane soba prostor trpljenja mlade žene Melite, potem ko se je morala poročiti s precej starejšim in premožnim markizom, zato da so se starši rešili iz denarnih težav. Pred soprogom, ki mu je jasno povedala, da ga sovraži, ker jo je kupil, se je zapirala $\mathrm{v}$ sobo in ostajala sama s svojim trpljenjem tako dolgo, dokler ni spoznala, da mu je delala krivico. Večkrat je zapisano, da je slonela ob oknu in zrla v daljavo. Pogled skozi okno, ki sicer označuje mejo med notranjim in zunanjim prostorom, opozarja, da je ženska brez moške spremljave težko prestopila prag domače hiše in vstopila v javni prostor (Würzbach 2004: 53).

\footnotetext{
${ }^{8}$ France Koblar (1935: 257) je to besedilo označil kot »stritarjansko lirični roman«. Gre za novelo, katere naslov opozarja na žensko pripovedovalko, fragmentarno izpovednost in dnevniško formo, v katero so vključena tudi fiktivna pisma. S Stritarjevim Zorinom jo druži predvsem sentimentalizem. Pripovedovalka Irma je podobno kot Zorin prepričana, da je solzna dolina človeku usojena, vendar se pri tem ne sklicuje na Stritarja, temveč na Goetheja, navaja pa tudi misel italijanskega pesnika Silvia Pellica, da lahko razume nesrečo in občuti sočutje do trpečih, kdor je sam preživel vsaj en dan v otožnosti. Vzroke za svojo otožnost nadalje poišče v vzgoji, saj ji je mačeha v otroških letih prepovedovala smeh in zapovedovala, da se mora žalostiti tudi zaradi tujih grehov.
} 


\section{Idilični prostori kot romantične heterotopije in locus amoenus}

V pripovedni prozi Pavline Pajk je gibanje deklet bolj ali manj omejeno na dom in njegovo bližino (vrt, gaj, gozdno jaso), medtem ko soproge in samske ženske tudi potujejo ali se celo preselijo v druga mesta. ${ }^{9} \mathrm{~V}$ že navedenih pripovednih besedilih Pavline Pajk si bomo v nadaljevanju ogledali vlogo idiličnih prostorov in njihovo povezanost s prevladujočo rastlinsko metaforiko za dekle/žensko.

Idila (gr eidýllion) se v literarni vedi uporablja $\mathrm{v}$ dveh pomenih. V ožjem pomenu je oznaka za malo epsko zvrst v verzih ali v ritmizirani prozi, v širšem pomenu, kakor jo razumemo tudi v pričujočem prispevku, označuje vsako besedilo, ki tematizira slikovit prostorsko-statičen konstrukt samozadostnega in harmoničnega človekovega sobivanja $\mathrm{z}$ naravo (Kühnel/Holmes 2007: 340). ${ }^{10}$ Čeprav ima koncept idile svoje korenine še pri starejši bukolični tradiciji, ${ }^{11}$ veljata za njena utemeljitelja Teokrit in Vergil, ki sta postala temeljni zgled in vir domala vsem poznejšim evropskim ustvarjalcem idile. ${ }^{12}$ Idila se od renesanse naprej uporablja tudi kot sopomenka za eklogo, pastoralo in pastirsko poezijo, v vseh teh zvrsteh pa se zapisujejo tudi idilični opisi pokrajin. V 18. stoletju, ko je idila kot zvrst bolj ali manj izumrla, je prišlo do prenosa idilično-harmoničnega koncepta $v$ življenje meščanskih, malomeščanskih in vaških eksistenc. Kot prostorsko-statični konstrukt je dobila pomembno mesto v poetičnem realizmu 19. stoletja, kjer je uporabljena tudi kot medij družbene kritike (Delbrück 1990: 217).

Iluzija o srečnem in harmoničnem življenju nastane najpogosteje tako, da se človek umakne pred politično, socialno in družbeno resničnostjo ter usmeri pogled v preteklost (v mladost ali v otroštvo), ki jo v svojih predstavah idealizira (Tismar 1973: 8). Idilično življenje poteka v sozvočju z naravnim ciklom, čas se lahko meri tudi po družinskih praznikih (rojstni dnevi, poroka, krst idr.) (Kühnel/Holmes 2007: 340). Posameznikov in družbeni čas izgubljata veljavo ali sta celo povsem ukinjena. Na tej podlagi predstavlja idila idejo o harmonični urejenosti narave, obenem potrebuje trdne omejitve prostora, zato so idilični prostori zagrajeni z imaginarnimi okviri, pri čemer so zelo priljubljene naravne omejitve, kot so gozdne enklave ali jame.

Opisi idiličnih prostorov so stilizirani in evocirajo mit o paradižu. Čeprav so pred stvarnostjo prostorsko zamejeni, jih ta vendar tudi ogroža in vdira vanje. Posledično se idila $\mathrm{v}$ realističnih besedilih razgrajuje in pojavlja le $\mathrm{v}$

\footnotetext{
${ }^{9}$ Arabela iz istoimenskega romana spremlja v tujino svojega soproga, samska vzgojiteljica Leonora iz novele Roka in srce potuje tudi sama. Posebno mesto v prostorski osvoboditvi ženske zavzema Malvina iz romana Slučaji usode. Ko jo zapusti mož, z otrokom odpotuje v Gradec in tam nekaj časa sprejme tudi mesto delavke, da se lahko preživlja.

${ }^{10}$ Kot prostorsko določen artefakt se je idila umestila tudi v geopoetske in ekokritiške raziskave (Marszałek/Sasse 2010: 12).

${ }^{11}$ Diekkämper (1990: 1) navaja za začetnika idile Hezioda.

12 Opazne sledi evropske idilične tradicije najdemo tudi v opisu svetopisemskega paradiža, v Homerjevi Odiseji, pri Ovidiju, Horaciju in drugih avtorjih (Schneider 1988).
} 
posameznih prvinah. V primerjavi s konkretnim in podrobnim opisovanjem lepih in manj lepih izsekov iz stvarnosti, k čemur teži realistična književnost 19. stoletja, predstavljajo idilični opisi njeno nasprotje. Prostorski konstrukti idile, ki uporabljajo posebne narativne strategije, kot so izolacija, poenostavljanje, imitacija in okrepitev posameznih motivov, se vzpostavljajo na kontrastih preprosto/zapleteno, narava/kultura, vas/mesto, lahko tudi predmestje/mesto, kot se pokaže npr. v romanu Arabela Pavline Pajk. Funkcija nasprotja je razvrednotenje enega in povzdigovanje drugega prostora. ${ }^{13}$

Od antike naprej predstavlja prototip idiličnega prostora locus amoenus. ${ }^{14} \mathrm{~S}$ tem pojmom je označena fiktivna idealna pokrajina, ki vsebuje vsaj tri stereotipne elemente: travnik, drevo in vodni vir. Običajno se pojavljajo še pomladne cvetlice in ptičje petje. Osrednji del tega toposa predstavlja senčno mesto z drevesi in vodo, ki obljublja prijeten hlad. Idilični opis narave ustvarja oziroma posreduje mir in harmonijo, zato vanj ne sodijo negativni naravni in atmosferski pojavi, kot so npr. veter, vročina, nevihta ali poplava (Dikkämper 1990: 2). Na locus amoenus, ki so ga $\mathrm{v}$ romantiki zamenjali opisi divje in eksotične narave, so oprti francoski vrtovi 18. in 19. stoletja. Prav v stiliziranih opisih vrtov in gajev se prvine tega toposa zapisujejo tudi v pripovedni prozi Pavline Pajk.

\section{Vrtovi, gaji, gozdne jase, podstrešje in klet}

Po Foucaultu predstavlja vrt najmanjšo totaliteto sveta in je najstarejša tovrstna heterotopija. Vrt je bil bolj ali manj edini prostor, ki je ženskam, dokler niso imele vstopa $\mathrm{v}$ poklicno in javno življenje, omogočal izhod iz hiše. Predstavljal je njen podaljšek oziroma prehodno mejo med zasebnim in javnim, tudi med naravo in civilizacijo. Opisi vrtov in gajev kot kulturno in estetsko preoblikovane narave se pri Pavlini Pajk naslanjajo na locus amoenus in vsebujejo bele, s peskom posute potke, cvetlične gredice, lope s prijetno senco, ribnik ali vodnjak. ${ }^{15}$

V noveli Roka in srce na primer se na ozadju ljubezenske zgodbe pojavi želja mestnega človeka po zdravem preživljanju poletnih počitnic v naravi. Vzgojiteljica Leonora že več let prihaja na počitnice k prijateljici v podeželsko grajsko okolje. Sprehaja se po cvetličnem in sadnem vrtu, v katerem se nahajajo tudi čebele, ki predstavljajo prototip harmoničnega življenja v naravi. Lopa na vrtu ne ponuja le prijetne sence za počitek, ampak je tudi prostor za naključna

${ }^{13}$ Prim. npr. Tavčarjevo povest Cvetje v jeseni.

${ }^{14} \mathrm{~V}$ antični literaturi označuje locus amoenus lepo oblikovano naravno kuliso z oživljenimi predstavami o utopični srečni deželi, v kateri vladata mir in harmonija. Čeprav ga najdemo že pri Homerju, se je kot termin uveljavil šele pri Vergilu in dobil pomembno vlogo pri ubeseditvi literarne pokrajine od antične bukolične poezije, prek srednjeveških epov in baročne poezije vse do začetka romantike (Fuchs - Jolie 2007: 459).

${ }^{15}$ V romanu Slučaji usode sta za gaj, ki ponuja zatočišče pred poletno vročino, uporabljeni metafori zeleno stanovanje in lepa božja narava, ki namiguje na svetopisemski paradiž. 
ali dogovorjena srečanja ter za zaupne pogovore. Leonora na primer prav tam prepričuje Melito, naj se žrtvuje za mater in poroči z markizom.

Podobne značilnosti ima vrt v romanu Arabela, katerega dogajanje je postavljeno na Moravsko. Takoj na začetku je opisano predmestje (najbrž Brna), ki nima konotacij socialnega obrobja, ampak ponuja v primerjavi z mestom svež zrak in zdravo življenje. Tam, v prijetnih vilah ob gozdu, prebivajo premožne, večinoma trgovske družine. Do teh vil vodi široka in $\mathrm{z}$ drevoredom obdana cesta, vsaka hiša ima tudi svoj vrt, ki je opisan kot lep in zamejen prostor z gredicami, lopo in vodnjakom. Karpeles na primer ob oddaji dela svoje vile najemniku posebej poudari pomen vrta za zdravo življenje, njegovo urejenost in pripadnost $\mathrm{k}$ hiši, zaradi česar se je po njem mogoče sprehajati v domači obleki. V omenjenem romanu se v velik vrt ${ }^{16} \mathrm{~s}$ kolibo, ki je pravo zavetišče pred pripekajočo poletno vročino, najpogosteje zateče Arabela. Ob neki priložnosti v senčni lopi tako zamaknjeno bere knjigo, da ne opazi bližajoče se nevihte, ki zmoti harmonijo vrta in nakazuje razgradnjo iluzijskega prostora:

Arabela je sedela $v$ majhnej kolibici na zadnjem konci vrta in čitala iz knjige. Da bi se bila sprehajala, čutila se je preveč utrujeno vsled vročine. Bila pa je v knjigo tako zamaknjena, da še niti zapazila ni, da se nebo vedno bolj temni in da se tam za gorami blisk za bliskom menja, gotovo znamenje bližnje nevihte (Pajk 1885: 178).

V romanu Arabela sta zapisani tudi heterotopiji deviantnosti, to sta podstrešje in klet kot zadnji bivališči blazne ženske, skrite pred javnostjo, za katero se skozi zgodbo izkaže, da je Arabelina mati. ${ }^{17}$ Obe omenjeni heterotopiji sta zamejeni in zaprti, vendar s prvimi prostori na poseben način tudi povezani, tako da razbijata iluzijo o urejenosti meščanske družbe in njenih institucij, razgaljata lažno družinsko moralo, kažeta na versko nestrpnost kakor tudi na nasilje nad ženskami in duševnimi bolniki.

Pavlina Pajk je izraz idila ${ }^{18}$ dvakrat uporabila v naslovu svojih pripovednih besedil. Pod vtisom daljšega bivanja v Bovcu je leta 1894 napisala Planinsko idilo. Izšla je naslednje leto v Knezovi knjižnici. Naslov napoveduje žanr planinske idile, vendar povest ne pripoveduje o idiličnem življenju v planinah, temveč o ljubezni rejenke Alenke v idiličnem, s planinami obdanem bovškem

${ }^{16}$ Pred poletno vročino se na ta vrt pogosteje zatečeta tudi zdravnikova žena in njen sin, ki se posebej zanima za naravo in zdravo življenje. Med drugim raziskuje planete, zahteva redno prezračevanje svoje sobe, spi ob odprtem oknu, nekaj časa je bil tudi prepričan vegetarijanec.

${ }^{17}$ Zgodba Arabeline matere je grozljiva. Kot pripadnica židovske vere je imela s pripadnikom katoliške vere otroka in je želela postati tudi sama katoličanka. Toda Žid Karpeles, njen polbrat, ji je to preprečil. V dvoboju je ubil Arabelinega očeta, njej pa odvzel otroka in jo zaprl na podstrešje, kjer je zblaznela. Ločena od otroka, izbrisana iz družine in popolnoma razčlovečena je prebivala za zaprtimi vrati podstrešja, v smradu, mrazu, umazaniji in lakoti. Ko je zanjo zvedela Arabela in ji nekaj časa na skrivaj stregla, so jo preselili v temno in vlažno klet, kjer je umrla.

${ }^{18}$ Ob Planinski idili je Pavlina Pajk napisala tudi Usodno idilo in jo namenila za Dom in svet, vendar je bila zavrnjena in je ostala v rokopisu (Koblar 1935: 258). 
trgu. V ljubezensko zgodbo je vključen diskurz o svežem planinskem zraku sredi poletne vročine, o lepoti bližnjih planin in razvijajočem se planinskem turizmu. V ta idilični trg pride iskat svoj duševni mir tudi ogrski graščak. Opis njegovega sprehoda do vznožja visoke planine in do slapa je primer romantičnega opisa neokrnjene narave, opozarja pa tudi na prežečo nevarnost:

Že sta prišla pod vznožje visoke planine. Kamen nad kamnom, skala nad skalo je tam stala nakopičena; iz njih bujno poganjajo divje rastline in planinske cvetlice. Po tem kamenju so skakale koze prijazno meketaje, plašne, radovedne oči upiraje na prišleca. Skalnati velikan nad njuno glavo se je zdel, kakor bi se hotel vsak trenutek porušiti. Po zrakovju šumi, drvi votlo grmenje padajočega slapa, ki se nenadoma prikaže njunim očem (Pajk 1895a: 118).

Življenjski prostori osrednje literarne osebe, rejenke Alenke, so omejeni na domačo hišo in na bližnjo trško okolico. Večino časa se zadržuje v svoji sobi, pomaga stricu na pošti in teti v gostilniški kuhinji. Prosti čas preživlja na svežem zraku s posedanjem na vrtu ob majhnem ribniku ali se sprehaja po bližnjem gozdu. Vrt s klopjo v senci, z ribnikom, s cvetočimi rožami in z drugimi rastlinami je opisan po matrici locusa amoenusa:

$\mathrm{Na}$ domačem vrtu zdaj sedi poleg majhnega ribnika in plete venec za krsto. Bilo je najlepše poletensko jutro. V okolici se ponosno dvigajo visoke planine, moleč s svojimi sivimi vrhovi v prozračno modro nebo. Iz daljave se čuje raznovrstno klenkanje zvončkov pasoče se živine (Pajk 1895a: 110).

Podobno vlogo ima tudi prijetno senčna jasa sredi gozda in je ob vrtu glavni kraj dekletovega počitka ali ročnega dela, njenih čustvenih sanjarij, zaupnih pogovorov in ljubezenskih izpovedi. V primerjavi z dekliško sobo, ${ }^{19} \mathrm{ki}$ je opisana kot tempelj devištva, imata oba idilična prostora značilnosti alternativne heterotopije.

\section{O metafori ŽENSKA JE RASTLINA/ROŽA}

V izbrani pripovedni prozi Pavline Pajk žensko in idilične prostore povezujejo rože. Na primer Alenka v Planiski idili se največkrat pojavlja v bližini rož in drugih rastlin, na vrtu si jih ogleduje ali uživa ob prijetnih vonjih, spet drugič sedi na klopci ob ribniku, premišljuje, bere knjigo ali plete cvetlični venček. Ženska v cvetličnih vrtovih in gajih ali na gozdni jasi je razumljena kot del narave. Tudi prispodobe in metafore za žensko temeljijo skoraj brez izjeme na konceptualni metafori ŽENSKA JE RASTLINA/ROŽA. Po stopnji metaforičnosti se umeščajo med tradicionalne in klišejske metafore, ${ }^{20}$ vendar bi bilo na podlagi

${ }^{19}$ Moškemu vstop v dekliško sobo ni bil dovoljen. V Planinski idili Hilarij ob prihodu z Dunaja ne vstopi v Alenkino sobo, ampak jo pozdravi skozi tesno zaprta vrata.

${ }^{20}$ Prim.: »Razcvela se je v mično dekle, mičnejšo, nego je obetal njen malovažni otročji obraz« (Pajk 1895a: 156). 
konkretnih analiz metafore zanimivo ugotoviti, koliko so bili sodobniki Pavline Pajk v metaforizaciji ženske izvirnejši.

V literarni tradiciji so cvetlične metafore in prispodobe pogosto uporabljene za ponazarjanje ženske lepote. Vendar Pavlina Pajk s tovrstnimi primerami ponazarja predvsem minljivost dekliške lepote, lahko tudi telesno šibkost, sramežljivost ali čustveno vznemirjenost dekleta. ${ }^{21}$ Dekliški liki se v izbranih pripovednih besedilih Pavline Pajk namreč ne odlikujejo po telesni lepoti, na kar opozarja tudi Katja Mihurko Poniž (2011: 77). Za Arabelo je v romanu celo posebej poudarjeno, da ni lepa. Pisateljica pripisuje dekletom predvsem tiste značilnosti in vrednote, ki so v skladu $\mathrm{z}$ dekliško vzgojo in matrico sentimentalnega pripovedništva, kot so plemenit in blag značaj, religioznost ali sočutje do vseh ubogih in trpečih živih bitij. Rastlinske/cvetlične metafore, ki ponazarjajo minljivost ženske lepote, ne govorijo zgolj o ženski, temveč tudi o družbeno omejeni recepciji ženske, o tem, da je ženska v okviru prevladnih dvojic kultura/narava, duh/telo oziroma razum/čustvo pojmovana le v območju narave in naravnega ciklusa, ne pa tudi kot razumsko in duhovno bitje. ${ }^{22}$

\section{Sklep}

V realistični literaturi je beg $\mathrm{v}$ idilične prostore pogosto tematiziran kot zavesten umik iz družbe, kot zatiskanje oči pred odgovornostjo in socialno resničnostjo ali kot svojevrstna kritika družbe. Meščanske pripovedi Pavline Pajk ne pripovedujejo o tem, saj njeni ženski liki še niso vključeni v družbo in živijo bolj ali manj v zaprtih družinskih prostorih ali okrog njih. Idilični prostori (vrtovi, gaji in gozdne jase), v katere se zatekajo ženski liki Pavline Pajk, so v vlogi romantičnih heterotopij in vsebujejo prvine locusa amoenusa. Opisani so kot prostori iluzije, harmonije, počitka, branja, premišljevanja, a tudi naključnih ali dogovorjenih srečanj z moškim, ki za dekleta v sobi kot svetišču devištva niso bila dovoljena. Ti prostori ponujajo tudi bivanje na svežem zraku in v prijetni vegetaciji, predstavljajo alternativo nezdravemu življenju v mestu in izražajo hrepenenje meščanskega človeka po podeželski idili (Arabela, Planinska idila). V izbranih pripovednih besedilih Pavline Pajk se obenem nakazujejo prvi odmiki od idilične podobe vrta. Harmonijo na vrtu lahko zmoti nevihta (Arabela), v romanu Slučaji usode ${ }^{23}$ postane vrt tudi prizorišče nasilja in samomora. Precej pogosta tradicionalna rastlinska/cvetlična metaforika za žensko ne govori le o

${ }^{21}$ Prim.: »Pri tem delu ji lica gore, da je bila bolj rdeča nego škrlatne pelargonije, koje zaliva« (Pajk 1895a: 131); »je trepetala po vsem životu kakor nežna trepetlika« (Pajk 1895a: 131).

22 Prim.: »Pač škoda, da bi tako redka cvetica kar tako ovenela, ne da bi koga osrečevala s svojo plemenito vonjavo, mislil je čestokrat. Ah, kako bi on hotel vzgojevati, obožavati to cvetko, ko bi kdaj postala njegova« (Pajk 1895a: 157).

${ }^{23}$ Malvinin mož Leopold, ki je po umoru zamorca prevzel njegovo identiteto, poskuša na vrtu zadaviti Avrelijo in se tam tudi sam ustreli. 
ženski ali o konvencionalnosti pisateljičinega sloga, temveč tudi o razumevanju ženske v družbeno-kulturnem kontekstu 19. stoletja.

\section{VIRI IN LITERATURA}

Hansgerd DELBRÜCK, 1990: Idylle. Metzler Literatur Lexikon. Begriffe und Definitionen. Ur. Günter und Irmgard Schweikle. Stuttgart: Metzler. 217-218.

Birgit DIEKKÄMPER, 1990: Formtraditionen und Motive der Idylle in der deutschen Literatur des neuzehnten Jahrhunderts. Bemerkungen zu Erzähltexten von Joseph Freiherr von Eichendorff, Heinrich Heine, Friedrich de la Motte Fouqué, Ludwig Tieck und Adalbert Stifter. Frankfurt am Main: Peter Lang Verlag.

Fran ERJAVEC, Pavel FLERÈ, 1926: Starejše pesnice in pisateljice. Izbrani spisi za mladino. Ljubljana: Učiteljska tiskarna.

Michel FOUCAULT, 2007: O drugih prostorih. Življenje in prakse svobode. Izbrala in uredila Jelica Šumič - Roha. Ljubljana: Filozofski inštitut ZRC SAZU. 214-223.

Susi K. FRANK, 2010: Geokulturologie - Geopoetik. Definitions- und Abgrenzungsvorschläge. Geopoetiken. Geographische Entwürfe in den mittel- und osteuropäischen Literaturen. Berlin: Kulturverlag Kadmos. 19-42.

Stephan FUCHS - JOLIE, 2007: Locus amoenus. Metzler Lexikon Literatur. Ur. Dieter Burdorf, Christoph Fasbender, Burkhard Moennighoff. Stuttgart, Weimar: Verlag J. B. Metzler. 459.

Miran HLADNIK, 1981: Slovenski ženski roman v 19. stoletju. Slavistična revija 29/3, 259-296.

France KOBLAR, 1935: Pajkova Pavlina. Slovenski biografski leksikon. 6. zvezek. Mrkun-Peterlin. Ur. Franc Ksaver Lukman. Ljubljana: Zadružna gospodarska banka. 257-259.

Jürgen KÜHNEL in Susanne HOLMES, 2007: Idylle. Metzler Lexikon Literatur. Ur. Dieter Burdorf, Christoph Fasbender, Burkhard Moennighoff. Stuttgart, Weimar: Verlag J. B. Metzler. 340-341.

Fran LEVSTIK, 1994: Popotovanje iz Litije do Čateža. Kratka proza slovenskega realizma. Ur. Gregor Kocijan. Ljubljana: DZS. 54-81.

Magdalena MARSZAŁEK in Sylvia SASSE, 2010: Geopoetiken. Geopoetiken. Geographische Entwürfe in den mittel- und osteuropäischen Literaturen. Ur. Magdalena Marszałek in Sylvia Sasse. Berlin: Kulturverlag Kadmos. 7-18.

Katja MIHURKO PONIŽ, 2011: Trivialno in/ali sentimentalno? Slavistična revija 59/1, $65-82$.

Pavlina PAJKOVA, 1893: Občutki na novega leta dan. Zbrani spisi Pavline Pajkove. 1. zvezek. Tiskal, izdal in založil Dragotin Hribar. V Celji. 117-123.

--, 1893a: Odlomki ženskega dnevnika. Zbrani spisi Pavline Pajkove. 1. zvezek. Tiskal, izdal in založil Dragotin Hribar. V Celji. 124-187. 
--, 1893b: Roka in srce. Zbrani spisi Pavline Pajkove. 2. zvezek. Tiskal, izdal in založil Dragotin Hribar. V Celji. 1-55.

- -, 1885: Arabela. Kres. 1-9, 6-75, 121-129, 177-189, 225-235, 281-289, 329-388, 385-391, 441-450, 489-496, 545-550 (http://www.dlib.si/details/URN:NBN:SI:DOC-MZW1GNRU/?query=\%27source $\% 3 \mathrm{~d} \%$ c4\%8dasopisje $\% 40$ AND $\% 40$ srel $\% 3 \mathrm{dKres}$ $\% 27 \&$ browse $=\% \mathrm{c} 4 \% 8$ dasopisje \&sortDir $=$ DESC\&sort $=$ date \&node $=$ besedila $\% 2 \mathrm{f} 1 \& p-$ ageSize=25\&fyear=1885). Dostop: 7. 4. 2012.

- -, 1895a: Planinska idila. Knezova knjižnica. Zbirka zabavnih in poučnih spisov. 2. zvezek. Ur. Fran Levec. Ljubljana.

- -, 1897: Slučaji usode. Uredil in izdal Andrej Gabršček. V Gorici.

Helmut J. SCHNEIDER, 1988: Deutsche Idyllentheorien im 18. Jahrhundert. Tübingen: Gunter Narr Verlag.

Jeans TISMAR, 1973: Gestörte Idyllen. Eine Studie zur Problematik der idyllischen Wunschvorstellungen am Beispiel von Jean Paul, Adalbert Stifter, Robert Walser und Thomas Bernhard. München: Carl Hanser.

Natascha WÜRZBACH, 2004: Raumdarstellung. Erzähltextanalyse und Gender Studies. Ur. Vera Nünning in Ansgar Nünning. Stuttgart, Weimar: Verlag J. B. Metzler. 49-68.

\section{IDYLLIC SPACES AS OTHER SPACES IN THE NARRATIVE PROSE BY PAVLINA PAJK}

After her first published novelette entitled Prva ljubezen (First Love) (Soča 1873) Pavlina Pajk (1854-1901) created a comprehensive narrative body of work. In the stories, narratives and novels, following in the example of sentimental storytelling, the center of her literary interest was the depiction of love, marriage and family life of the bourgeois woman. Selected texts of her bourgeois prose (Odlomki iz ženskega dnevnika (Excerpts from the Diary of a Woman), Zora 1876; Roka in srce (Hand and Heart), Kres 1881; Arabela, Kres 1885; Planinska idila (Mountain Idyll), Knezova knjižnica 1894; Slučaji usode (Strikes of Fate)) recall her interest also in themes which talk of compassion towards all who suffer, the talk about Jews, the social situation of single women, healthy life, vegetarianism and the expansion of mountain tourism.

In this paper, selected narrative texts by Pavlina Pajk are shown to demonstrate links between the concept of idyllic spaces, the presentation of the female character and the conceptual metaphor WOMAN IS A PLANT. The maiden characters usually behave in accordance with the requirement of traditional upbringing, but they strongly resist entering marriage without love, while in life they want to be happy and loved. Up to maturity they remain more or less confined to their family houses and the space surrounding them. They keep to themselves in their rooms, write diaries, lean on window sills or take walks through the garden and its environs. The so-called woman's spaces (gardens, ponds, wooded clearings, avenues, etc.) are idyllic constructs of nature with individual elements reminiscent of "locus amoenus," and they usually take on the role of romantic heterotopias. They are described as places of first amorous meetings, places for reflection, rest, reading, etc. In the novel Slučaji usode the garden as an illusionary space is already dissolved. Unlike the idyllic places, the prose by Pavlina Pajk reflects also heterotopias 
reminiscent of the "locus teribles" (the attic and basement in the novel Arabela). The quite common traditional plant metaphors for women appear in the role of the herald of the transience of feminine beauty. This metaphor, however, is far from speaking merely about the woman or the conventionality of its author's style. It implicitly also conveys criticism of the society, which places the woman solely in the sphere of nature. 